\title{
O QUE É O OBJETO “MORADIA” DO PROGRAMA MINHA CASA MINHA VIDA?
}

\section{WHAT IS THE "HOUSING" OBJECT OF THE MINHA CASA MINHA VIDA PROGRAM?}

\author{
Josué Mastrodi ${ }^{1}$ \\ Suzana Maria Loureiro Silveira Zaccara ${ }^{2}$
}

\section{Resumo}

O direito à moradia e o direito ao planejamento urbano ainda não são afirmados como direitos subjetivos ou como direitos fundamentais de aplicação imediata. A exigibilidade desses direitos, assim como dos demais direitos sociais, só é possível a partir da definição de uma política pública. Neste artigo, apresentamos crítica ao Programa Minha Casa Minha Vida como política pública incapaz de reduzir o déficit habitacional das famílias mais vulneráveis, que se encaixam na categoria de "até três salários mínimos". Nesta faixa de renda, ainda há 82,5\% de déficit habitacional. As famílias com renda de zero a cinco salários mínimos perfaziam juntas, em 2012, o total de $92,6 \%$ do déficit habitacional urbano. O déficit habitacional dentre os números colhidos pela Fundação João Pinheiro é de 5,430 milhões de domicílios, segundo estimativa do PNAD, e há pouco mais de 6 milhões de domicílios disponíveis hoje no Brasil. A política habitacional do Minha Casa Minha Vida serve à construção de novas residências, postas no mercado imobiliário segundo as regras desse mercado e não visando efetivamente à concretização do direito à moradia. Este acaba se subordinando ao direito de propriedade, e apenas quem tem condições de pagar pelo imóvel pode se beneficiar desse programa.

Palavras-chave: Direito à moradia. Programa Minha Casa Minha Vida. Moradia pela concessão de propriedade. Direito à cidade. Planejamento urbano.

\begin{abstract}
The right to housing and the right to urban planning have not been stated as subjective rights or as fundamental rights of immediate application. The enforceability of these rights, as well as other social rights, is only possible from the definition of a public policy and within its limits. In this paper, we present criticism to the housing Public Program called Minha Casa, Minha Vida as a public policy unable to reduce the housing deficit of the most vulnerable families who earns up to three minimum wages. In this income range, there are still $82.5 \%$ of housing deficit. Families with income from zero to five minimum wages accounted together, in 2012, the total of $92.6 \%$ of the urban housing deficit. The housing deficit identified by the João Pinheiro Foundation is about 5.430 million houses, according to estimates by the National Household Survey, and there are about 6 million homes available for housing in Brazil. The housing policy of Minha Casa, Minha Vida serves to the construction of new homes that are put in the real estate market in accordance to the rules of this market that does not match the implementation of the right to housing. The outcome of this public policy subordinates right to housing to the right to property, and only those who can afford the property can obtain any benefit from this program.
\end{abstract}

Keywords: Right to housing. Minha Casa, Minha Vida Program. Housing concession by producing properties. Right to the city. Urban planning

\footnotetext{
${ }^{1}$ Professor da Faculdade de Direito e do programa de Pós-Graduação Stricto Sensu em Sustentabilidade (Pontifícia Universidade Católica de Campinas). E-mail: mastrodi@puc-campinas.edu.br

${ }^{2}$ Bolsista da Fundação de Amparo à Pesquisa do Estado de São Paulo. E-mail: sszaccara@gmail.com
} 


\section{INTRODUÇÃO}

Ao encarar a moradia como porta de acesso a demais direitos reconhecidos por uma determinada ordem jurídica, nasce a necessidade de entender tal postulado social como elemento integrador das pessoas ao território da cidade como representação social. É neste sentido que o presente trabalho foi delineado. ${ }^{3}$

Voltados à necessidade de afirmar a moradia como um direito autônomo e passível de concretização, uma das questões objeto de nosso Grupo de Pesquisa institucional, na qual se insere a presente análise, foi justamente identificar o elemento posse do direito fundamental à propriedade; a partir disso, levantamos algumas indagações que nos fizeram refletir sobre como apartar o direito à moradia do direito à propriedade, uma vez que a moradia costuma ser identificada com o uso efetivo da coisa (equivalente ao elemento posse do direito à propriedade; cf. MASTRODI e BATISTA, 2015).

Nesse sentido, a discussão aqui apresentada está voltada à promoção do direito à moradia a partir da atuação estatal, mediante a definição e a implementação de políticas públicas habitacionais. Em especial, um dos nossos objetivos foi o estudo do Programa Minha Casa Minha Vida (PMCMV) e como esta forma de se produzir novas unidades residenciais tem se mostrado muito mais uma reprodução institucionalizada de acesso à propriedade.

Para fins deste artigo, a ideia é justamente de proteger a moradia (identificada, na teoria do direito, pela posse do imóvel) mesmo quando o direito à moradia estiver em conflito, no caso concreto, com o direito do proprietário do imóvel ou com interesses públicos: atualmente, em caso de desapropriação, o proprietário é indenizado, mas ao morador sem justo título nada é devido pela perda do direito à moradia. Vê-se que este direito não possui muita garantia. Tanto que o Comitê das Nações Unidas para os Direitos Econômicos, Sociais e Culturais propugna que moradia deve ser um direito a partir da garantia de posse conferida pelo Estado ao seu morador. ${ }^{4}$ Garantia de posse, e não de propriedade.

\footnotetext{
3 Inicialmente, é preciso mencionar que o presente texto é fruto de um ano de pesquisa fomentada pela Fundação de Amparo à Pesquisa do Estado de São Paulo (FAPESP). Nesse sentido, o presente estudo reflete a segunda parte dos resultados alcançados durante a pesquisa. Cumpre salientar que a primeira parte desse estudo foi publicada em periódico nacional indexado com Qualis A1 no Estrato Direito (data de publicação e nome do periódico suprimidos em observância à avaliação dupla cega).

${ }^{4}$ Na Recomendação no 7 desse mesmo Comitê da Nações Unidas para os Direitos Sociais, Econômicos e Culturais, de 20 de maio de 1997, está afirmado desde seu item no 1: "Em sua Recomendação no 4 (1991), este Comitê observou que todas as pessoas deveriam possuir um grau de segurança de posse que garanta proteção legal contra eviç̧ões forçadas, assédios e outras ameaças".
} 
Desenvolvemos esta pesquisa em três partes. No item 1, logo abaixo, tratamos da relação entre a política habitacional desenvolvida a partir do PMCMV e a política urbana, momento em que identificamos certa dissociação entre planejamento urbano voltado à construção da cidade e a produção de novas moradias, produção esta realizada à revelia de qualquer planejamento estatal. No item 2, em seguida, tratamos especificamente das características fundamentais do PMCMV, política pública apresentada como voltada à promoção do direito à moradia, mas que acaba por promover esse direito de forma completamente associada à produção e à transferência de propriedades imobiliárias, garantidas por financiamento bancário, numa estrutura que impede a promoção desse direito às famílias que efetivamente mais precisariam de alguma política habitacional. Na terceira parte, tratamos de proceder a análise de dados relativos ao déficit habitacional e à constatação de que o PMCMV não serve à redução desse déficit, em especial no que respeita às famílias com faixa de renda de zero até 3 salários mínimos.

O modelo de ocupação de solo promovido pelo PMCMV nas regiões metropolitanas do Brasil está relacionado em parte ao fenômeno do êxodo rural, ${ }^{5}$ em que os retirantes, por não deterem recursos econômicos que Ihes permitam fixação em espaços urbanos servidos por equipamento públicos, acabam por ocupar, formal ou informalmente, áreas ilegais, ou locais distantes de serviços públicos e de oferta de empregos, ou imóveis cujos donos não Ihes davam destinação ou finalidade social (cf. MASTRODI e SILVEIRA ZACCARA, 2016, p. 3).

Esta questão da formação de assentamentos habitacionais (in) formais e os locais onde se constituem, às margens das cidades ou nos próprios centros urbanos, alcançadas ou não pelo mercado privado de habitação, é um tanto quanto controversa. Brevemente, podemos citar três aspectos de constituição de assentamentos urbanos, tendo por pauta a questão habitacional: o primeiro seria a ocupação habitacional informal em locais que ainda não foram apropriados, que geralmente estão localizados "fora" ou à margem da cidade (não só favelas, mas também casas rudimentares em subúrbios afastados ou cidades-dormitório); o segundo seria outra forma de ocupação informal, mas nos centros urbanos, como é o caso das ocupações havidas em hotéis, prédios públicos desativados e quaisquer outros imóveis não utilizados nos centros das metrópoles brasileiras; já o terceiro, parte do recorte deste artigo, é o caso do PMCMV, ocupação formal no

\footnotetext{
${ }^{5}$ Os autores se apoiam no desenvolvimento teórico realizado por Lefebvre (2001); Singer (1985) e Wood (2000), a respeito da urbanização, como fenômeno social, ter impulsionado a organização dos espaços urbanos de uma maneira ou de outra (especialmente pela falta de estrutura do Estado), de modo a não permitir a fixação de determinados grupos à terra (antes isso era visto no campo, motivo pelo qual um exército de camponeses sem ter como sobreviver no meio rural foi compelido a se retirar para as cidades)
} 
espaço "urbanizado" ou passível de urbanização (que é uma das condições para a aprovação dos empreendimentos), mas igualmente à margem da cidade.

No primeiro aspecto, a realidade social aponta para a formação de subúrbios e favelas no entorno não urbanizado das cidades e regiões metropolitanas, locais estes despidos de infraestrutura urbana e caracterizados pela apartação relativa de áreas centrais, em que se concentram empregos e oferta de serviços "formais". Nesse sentido, teríamos uma modalidade de ocupação, tida por informal, em locais não apropriados pelo mercado imobiliário (tido como um mercado formal de habitação) que, geralmente, não interessa (de imediato) a este mercado, por estarem localizados ora em áreas de restrição legal, ora distantes de fatores que contribuem para uma maior circulação de bens e produtos.

No segundo aspecto, há também, sob a necessidade de um espaço em que se possa firmar moradia, ocupações igualmente informais, formadas por grupos sociais não alcançados pelas políticas habitacionais, em centros urbanos já alcançados pela oferta de serviços e proximidade de empregos, como é o caso das ocupações havidas em propriedades privadas não utilizadas nos centros das cidades, ou seja, em imóveis desocupados (seja por abandono, por especulação imobiliária ou por qualquer outro fator) que não cumprem sua função social.

Um terceiro aspecto destas formas de ocupação do espaço urbano se dá pela produção de habitações via PMCMV, modalidade de ocupação formal e legal, mas que se aproxima, por vezes, da ocupação informal em espaços segregados tanto dos grandes centros como de maiores oportunidades de integração social dos seus beneficiários, pois na busca de terrenos mais baratos, construtores e incorporadores tendem a se distanciar dos espaços urbanos já servidos por equipamentos públicos. Reconhecemos a relevância dos estudos relativos à produção de moradias (e à produção do espaço urbano) por meio de ocupações informais no entorno da cidade ou da metrópole, bem como nos centros degradados. Não obstante, esta pesquisa teve, por força de seu corte epistemológico, foco primordial na construção do espaço urbano por meio de políticas habitacionais desenvolvidas por agentes de mercado no âmbito do PMCMV.

Aproveitamos a oportunidade para agradecer às considerações apresentadas pelos revisores indicados pelo Conselho Editorial da Revista de Direito da Cidade, que contribuíram sensivelmente para o aprimoramento da redação deste artigo científico. 


\section{DA RELAÇÃO ENTRE A POLÍTICA HABITACIONAL E A POLÍTICA URBANA}

A compreensão da realidade atual só é possível a partir da noção de propriedade, base do Direito e da sociedade contemporânea, de sujeito de direitos, que são os proprietários. No entanto, ao que parece, apesar de se apontar a igualdade de tratamento normativo a todos os preceitos e valores constitucionais (no caso do nosso ordenamento jurídico), a propriedade sempre representará um peso, uma relevância maior que a posse. Segundo Abreu (2011), o que se tem visto é uma forte tendência dos tribunais brasileiros em se posicionarem reiteradamente no sentido de proteção, ampla e irrestrita, à propriedade (ainda que abstrata), relegando ao "banco dos réus" o direito à moradia (apesar de ser o reflexo do uso efetivo, da posse). Seu estudo teve como objeto os assentamentos informais e os despejos forçados, sob a ótica de processos judiciais concretos dos tribunais brasileiros.

Apesar de o direito à moradia, pela ordem jurídica, ser bastante adjetivado (humano, social, fundamental), enfatizamos que não se nota a mesma preocupação em conferir aos seus destinatários qualquer capacidade para exigi-lo. Assim, temos (ou melhor, não temos!) a moradia, declarada como um direito, humano, social, fundamental, porém não exigível. Torna-se exigível apenas quando houver previsão orçamentária ou definição da política pública. Além disso, a moradia não possui autonomia suficiente em relação ao direito à propriedade; isto é, não se consegue proteger a posse, pura e simplesmente, pelo fato de existir alguém com a expectativa de ser morador. Isso fica claro quando, para se proteger esse valor social à moradia, protege-se antes a garantia individual à propriedade com o título de propriedade imóvel. Nem mesmo o modelo de habitação federal vigente, o PMCMV, escapa dessa constatação: o PMCMV garante a moradia por meio da promoção da propriedade imobiliária.

Assim o é, em relação ao ordenamento jurídico brasileiro, pelo fato de os direitos sociais serem entendidos como normas programáticas e não regularem instantaneamente o conteúdo do seu objeto. Apesar disso, não é compreensível, muito menos razoável, privar alguém da satisfação imediata e direta de um direito por estar disposto em normas de caráter programático, uma vez que o Estado está adstrito a prestar positivamente os direitos e garantias inseridos na Constituição Federal. De acordo com Abreu (2011, p. 396), com a alteração do caput do art. 60 da CRFB, pela Emenda Constitucional 26/2000, o legislador apenas explicitou o status de direito fundamental que o direito à moradia já consagrava "por ser decorrência lógica e social do princípio da dignidade humana, que impõe a satisfação das necessidades existenciais básica da vida". Após esta emenda 
ao texto constitucional houve a edição do Estatuto da Cidade pela Lei no 10.257/2001, como forma de regulamentar a política urbana consagrada em 1988 nos artigos 182 e 183 do texto constitucional.

Abreu (2011, p. 396) afirma, também, que o Estatuto trouxe alguns "instrumentos urbanísticos" cujos reflexos acarretam na proteção do direito à moradia. Especificamente para fins deste trabalho, destacamos o previsto nos incisos I e XIV do artigo $2^{\circ}$ do Estatuto da Cidade, ${ }^{6}$ que consistem na garantia ao direito à cidade pelo acesso à terra urbanizada, à moradia, saneamento básico, infraestrutura urbana etc., bem como na necessária regularização das áreas ocupadas por grupos sociais de baixa renda.

O direito à moradia deve ser entendido como um primeiro degrau para a concretização do direito à cidade. Muito embora o direito à moradia tenha sido prescrito em normas de caráter internacional e em normas internas ao ordenamento jurídico brasileiro, essa elevada produção normativa não impediu o crescimento do déficit habitacional, que atinge índices elevados. Para Marra e Gonçalves (2011), isso se deve à falta de atenção para com as cidades pelo Poder Público, ainda que representem espaços de grande aglomeração de pessoas não são destinados recursos e serviços básicos suficientes. Segundo as autoras, a moradia não é encarada como parte da cidade ao se calcular o déficit habitacional, mas como "objeto particular da família que nela reside", em que são levados em consideração quesitos como: habitações precárias, coabitação familiar e ônus excessivo como o aluguel. No entanto, , o direito à moradia vai além de um "teto", e conforme os arquétipos estabelecidos por documentos internacionais deve compreender à satisfação de condições existenciais básicas necessárias à concretização de outros direitos fundamentais, como acesso a emprego, educação, mobilidade urbana e saúde (MARRA e GONÇALVES, 2011, p.58-60).

Há estrutura normativa que permite tratar o direito à propriedade como um direito autônomo. Desde documentos internacionais das Nações Unidas até a própria declaração constante do art. 6o, da Constituição da República Federativa do Brasil de 1988 (CRFB/1988), prescrevem a moradia como direito humano e fundamental, que deve ser promovido pelo Estado

\footnotetext{
${ }^{6}$ Estatuto da Cidade, Art. 2으 A política urbana tem por objetivo ordenar o pleno desenvolvimento das funções sociais da cidade e da propriedade urbana, mediante as seguintes diretrizes gerais:

I - garantia do direito a cidades sustentáveis, entendido como o direito à terra urbana, à moradia, ao saneamento ambiental, à infra-estrutura urbana, ao transporte e aos serviços públicos, ao trabalho e ao lazer, para as presentes e futuras gerações;

(...)

XIV - regularização fundiária e urbanização de áreas ocupadas por população de baixa renda mediante o estabelecimento de normas especiais de urbanização, uso e ocupação do solo e edificação, consideradas a situação socioeconômica da população e as normas ambientais;
} 
brasileiro visando à promoção exclusiva de moradias, independentemente de os beneficiários dessas moradias serem ou não proprietários dos imóveis que Ihes confiram habitação e segurança de posse. ${ }^{7}$

No entanto, a realidade social e as políticas públicas vigentes não conferem à moradia o caráter de direito fundamental autônomo: o direito à moradia tem sido assegurado apenas quando da garantia e preservação do direito à propriedade, pois é o que confere ao titular potencial para proteger a coisa contra quem quer que seja. O PMCMV não confere moradias senão pela entrega de propriedade imobiliárias. Não há segurança jurídica da posse ou da moradia de modo desvinculado do direito à propriedade.

A promoção de moradias, no entanto, não pode se dar de modo estanque da produção do espaço urbano. Planejar a cidade e promover habitação são políticas de inclusão social que devem se dar de modo integrado. Conforme Saldanha (1986, p. 22-31), a cidade pressupõe convívio de pessoas, e tal convívio só é possível pela inclusão dessas pessoas no tecido urbano.

Por outro lado, o território da cidade tem sido apropriado pelos grandes grupos econômicos, que se utilizam de estruturas de valorização imobiliária para organizar seus interesses de mercado. ${ }^{8}$ Isso é totalmente contrário ao interesse público, no sentido de promoção do direito à moradia de quem não tem condição de arcar com os custos de aquisição de imóveis.

Quando os espaços urbanos são apropriados, perde-se a chance de que tais espaços sejam utilizados segundo o interesse público de moradia. Caso a Administração Pública tenha interesse em promover moradia nesses espaços, a lógica de mercado impõe que tais espaços sejam negociados segundo a lógica da valorização imobiliária, segundo o valor da propriedade. Não é que a moradia não tenha um valor autônomo ao da propriedade, mas os espaços já foram precificados segundo valor de mercado.

A implementação da moradia adequada está vinculada à promoção do direito à cidade. No entanto, grosso modo, a moradia adequada deve necessariamente estar associada a um local em que existam possibilidades reais para o morador e a comunidade em que habita acessarem os recursos públicos e as vantagens oferecidas pela cidade. Em termos institucionais e jurídicos, para os fins deste trabalho, a compreensão do direito à cidade tem relação com a materialização do

\footnotetext{
${ }^{7}$ A esse respeito, cf. Mastrodi e Rosmaninho (2013); Mastrodi e Rossi (2014); Mastrodi e Rodrigues (2015). Nesses artigos, há farto desenvolvimento teórico sobre os documentos internacionais, desde o Pacto Internacional dos Direitos civis e Políticos, o Pacto Internacional dos Direitos Econômicos, Sociais e Culturais, as Recomendações Gerais n. 4 e 7 do Comitê das Nações Unidas, as Declarações de Toronto e Istambul (Agendas Habitat I e II).

${ }^{8} \mathrm{~A}$ respeito da captura do interesse público pelo interesse de mercado, cf. Mastrodi e Martins (2016).
} 
conjunto de direitos fundamentais sociais, constantes de forma explícita na redação do artigo 60 da CRFB $/ 1988 ;^{9}$ em outras palavras, o direito à cidade passa pela promoção do direito à moradia adequada. ${ }^{10}$

Pelo fato de o desenvolvimento urbano ter se pautado sob os princípios do laissez-faire, com o funcionamento do mercado livre de intervenções e com a proteção ampla e irrestrita da propriedade privada, alimentou-se a ilusão, liberal, de que a moradia seria assunto a ser tratado no mundo dos negócios, que a produção de moradias seria para todos, com uma única condição: o crédito: quando analisamos a conjuntura do PMCMV, os atores são pontuados nas figuras do Estado, do mercado privado (construtores, incorporadores e financiadores) e dos destinatários finais (beneficiários). A moradia, porém, só é concedida se e quando o crédito do futuro morador for aprovado (quem não tem crédito dificilmente tem acesso às moradias do PMCMV, ainda que seja dito que este programa seja feito para pessoas sem renda), e mesmo a definição da política habitacional imprescinde da definição dos recursos disponíveis.

Revela-se, deste modo, a dimensão política do PMCMV, indicada por Cardoso e Jaenisch (2014), ao tratar sobre o PMCMV na Região Metropolitana do Rio de Janeiro e seus contornos, especialmente, à época de grandes eventos esportivos, como foi o caso da Copa do Mundo (em 2014) e no caso das Olimpíadas (neste ano de 2016). Para os autores, o PMCMV foi ideologicamente pensado e vem sendo estruturado nos moldes de uma estratégia neokeynesiana com o intuito de relativizar os impactos causadores da crise econômica de 2008, o que o transformou em algo além da questão puramente habitacional. Ou seja, para estes autores citados, o contexto em que se insere o programa de habitação federal é parte de um "projeto político amplo", e conta com os atores mencionados anteriormente, mas centrado na indústria da "construção civil como elemento-chave para dinamização da economia e o consumo enquanto principal mecanismo de inclusão social" (CARDOSO e JAENISCH, 2014, p. 7).

\footnotetext{
${ }^{9}$ CRFB/1988. Art. 6o São direitos sociais a educação, a saúde, a alimentação, o trabalho, a moradia, o lazer, a segurança, a previdência social, a proteção à maternidade e à infância, a assistência aos desamparados, na forma desta Constituição.

${ }^{10} \mathrm{~A}$ este respeito encontra-se em desenvolvimento, em outra pesquisa: "Particularmente, concebemos que a cidade é o que acontece quando moramos e porque moramos. Se não morarmos, não convivemos, não há cidade. A noção de cidade é apresentada como ser possível experimentar e fazer parte do tecido urbano, isto é, ser (e estar) integrado socialmente àquele espaço de materialização de outros direitos. Se isso não se verifica, podemos indicar a existência moradias sem cidade, ao passo que moradia, como se pode extrair das resoluções do PIDESC, não pode ser qualquer uma, ou seja, aquela em total inadequação como o espaço urbano, mas deve ser digna, adequada" (MASTRODI e SILVEIRA ZACCARA, mimeo, 2015).
} 
Ao assim encará-lo, como parte de um projeto voltado à política econômica não interventiva, pois o Estado entregou ao mercado privado toda "preocupação" acerca da promoção deste direito social, distanciou-se de toda luta realizada até então realizada, luta esta responsável pela inclusão, no texto constitucional de 1988, das previsões relativas a política urbana em seus artigos 182 e 183.

Apesar de a moradia ser reconhecida como direito social, conforme o artigo 60 da CRFB/1988, Cardoso e Jaenisch pontuam que a concepção da política habitacional em que se inseriu o PMCMV levou tal direito a ser encarado segundo a lógica de mercado, pela qual a moradia passou a ser encarada "como um produto, um bem de consumo, ou um investimento financeiro" (CARDOSO e JAENISCH, 2014, p. 7). No mesmo sentido, essa mesma conjuntura de nãoingerência estatal fez Trindade (2012, p. 147) afirmar que até mesmo a função social da propriedade tem sido compreendida de acordo com os interesses do mercado, ao afastar o caráter social e lhe atribuir função econômica, compreendida pelo "enriquecimento de seus detentores".

Ao não controlar as políticas habitacionais, moradias são produzidas segundo a lógica de mercado, em espaços apropriados e precificados que transformam tanto o espaço urbano quanto as habitações em mercadorias postas à venda. Essa forma de produção do espaço urbano tem como subproduto, nos locais em que o mercado não ainda não alcança (em geral por proibições legais ou mesmo por falta de interesse econômico), a formação de ocupações precárias e informais, onde não há direito à cidade, seja porque o local ocupado possui restrições ambientais, seja porque o local é despido de quaisquer equipamentos ou serviços públicos.

Embora exista liberdade para construir e edificar, ainda que conferida aos que são proprietários (isto é, são estas pessoas que detêm a capacidade de usar, gozar e dispor da coisa, conforme disposto no artigo 1.228 do Código Civil de 2002), tal liberdade comporta exceções conhecidas como restrições ao direito de construir. Com a edição da Lei de Parcelamento do Solo Urbano n. 6.766 de 1979, houve a previsão formal a respeito da proibição quanto ao parcelamento do solo e expansão urbana em áreas definidas como de proteção ambiental, como prescrevem os incisos do artigo 3ำ, parágrafo único, por exemplo, às margens de cursos de água, nascentes e lagos, em encostas com declividade acima de 30\% etc. A esse respeito, Meirelles (1996; 2008) pontua questões ligadas ao direito urbanístico e como este ramo de direito público se destina à verificação e constatação de normas norteadoras da forma como os espaços voltados ao solo urbano e urbanizável devem ser transformados em locais habitáveis. 
Numa tentativa de acabar com as moradias de pobres, os cortiços, o poder público, por meio de legislações, estabelecia padrões mínimos, que muito provavelmente não seriam preenchidos pela classe proletária. Uma das medidas era a aprovação de plantas para a construção e com isso a documentação de propriedade do solo, conforme, por exemplo, previa a Lei Municipal da cidade de São Paulo no 38 de 1893, outra medida era a proibição de moradias coletivas, conforme Lei municipal no 375 de 1897, dentre tantas outras, como afirmou Maricato (2013, p. 150).

É interessante observar, conforme verificaram Moura e Mota (2015, p. 1299) que, no tocante às restrições legais impostas, por exemplo, pela Lei federal de uso e ocupação do solo no 6.766/1979, foi desconsiderada a realidade socioeconômica em que se encontram os indivíduos e, em decorrência disso, houve aumento na ocupação de áreas de preservação ambiental, fortalecendo o processo de ocupação excludente dos espaços urbanos. De todo modo, a política habitacional do PMCMV tem sido realizada pelos agentes de mercado em locais geralmente distantes da cidade, já que essa distância é justamente o que determina o acesso à terra barata. Os moradores dos conjuntos habitacionais do PMCMV podem até ter casa própria, mas não detêm os elementos que compõem o direito à moradia adequada. Esse modelo se pautou em tratar um direito social de maneira mercantilizada, como produto, subordinando-o aos interesses dos agentes do mercado imobiliário, que em poucas palavras pode ser entendido como lucro. O modo como o sistema se estruturou (conforme os ditames do capitalismo) dificulta a idealização e até mesmo a realização de uma política de moradia voltada apenas em função de alguém que é sujeito de direito destinatário do direito à moradia, sem que, para isso, tenha que portar um documento de direito obrigacional ou real que lhe confira 'isso'.

No mundo fático, o que existe é tão somente o direito de moradia sendo exercido à custa (no sentido de 'em razão de') do direito de propriedade, seja em casos de moradia por aluguel (alguém mora por que outro alguém é dono e aluga) seja pela aquisição do título de proprietário (por exemplo, por meio do PMCMV). Não obstante, é possível pensar, em virtude da autonomia dada ao direito à moradia tanto pela Constituição quanto por documentos normativos internacionais, na promoção de políticas de moradia pela moradia, e não pela propriedade. ${ }^{11}$

\footnotetext{
${ }^{11}$ Exemplo de uma política habitacional voltada à moradia pela moradia é exposta por MATTL (2013), que relata a respeito do Caso da Viena Vermelha, em que houve, na capital da Áustria, no intervalo compreendido entre os anos de 1923-1934, a criação de 350 conjuntos habitacionais, com cerca de 60 mil unidades de apartamentos. No ano de 1933 já estavam contabilizadas 554 mil casas em Viena. As unidades habitacionais mencionadas passaram a abrigar 200 mil moradores. Frente à população de Viena à época, em
} 


\section{O PROGRAMA MINHA CASA, MINHA VIDA}

\section{O Programa Minha Casa, Minha Vida (PMCMV) é o programa do Governo Federal de} provisão habitacional, instituído pela Lei n. 11.977 de 07 de julho de 2009, decorrente da Medida Provisória (MP) no 459/2009. A MP já disciplinava sobre a organização, estrutura e finalidade do PMCMV, bem como trazia a regularização fundiária de assentamentos humanos em zonas urbanas em suas disposições iniciais. Posteriormente, o PMCMV teve seu texto legislativo alterado pelas seguintes leis: em 1o de dezembro de 2010, a MP no 514/2010 deu origem à Lei 12.424, de 16 de junho de 2011 e, pouco mais de um ano após edição deste última Lei, houve nova retificação da lei instituidora do PMCMV, pela MP no570/2012, convertida 12.722, em 3 de outubro de 2012.

O PMCMV condensa em sua estrutura um feixe de outros subprogramas habitacionais organizados em categorias de ações que representam modos convergentes de "acesso ao produto", conforme pontuam AMORE et al (2015, p. 15), objeto do PMCMV, que é a aquisição da casa própria, são formas de financiamento, fundos, tipologias habitacionais, agentes operadores, todos os setores que determinam o caminho pelo qual percorrerá a política pública. Estas ações são denominadas pela Lei do PMCMV como subprogramas, espécies do gênero, pelos quais a

conta rápida, podemos indicar a seguinte proporção: de cada dez habitantes de Viena, um possuía moradia graças a essa política habitacional, se levarmos em consideração o contingente populacional de 2 milhões de habitantes. A política habitacional de Viena estava voltada à construção de alguns tipos de edificações, a exemplo dos conjuntos habitacionais de edifícios conectados por jardins e praças e das construções que visavam, pela integração entre os membros dos conjuntos, a ocupação dos espaços vazios entre os prédios voltados ao estabelecimento de locais de convivência, intencionalmente voltados à criação de vínculos sociais entre os que ali se encontravam (MATTL, 2013, p. 192-195). Continua o autor a discorrer sobre a forma de desenvolver a política, no tocante aos recursos financeiros que custeariam programas sociais (além da moradia, havia uma preocupação com outros direitos sociais, como a educação) e habitacionais: estes ficariam a cargo, quase que exclusivamente, da receita fiscal de Viena. De acordo com MATTL, a forma de organização das receitas apresentadas por este plano de Viena representou um impacto sobre o modo de formulação "para uma política urbana radical nos dias de hoje" (2013, p. 199). O Caso da Viena Vermelha mostrou a tomada de decisões no tocante ao interesse social de integração das pessoas, não apenas pelo fato de que programas habitacionais foram idealizados e materializados de modo a não onerar quem mais precisava da produção habitacional da forma como se deu (isto é, com a responsabilidade desta promoção nas mãos da municipalidade: o termo utilizado por MATTL é socialismo municipal). Nesse sentido, merece destaque para a pontuação do autor "Com o socialismo municipal, a própria administração da cidade assumiu os empreendimentos econômicos vitais para seu desenvolvimento, no intuito de limitar os danos causados pela economia de mercado. Toda a rede de infraestrutura passou para o poder e administração públicos, a começar pelo transporte público, eletricidade e gás. Além disso, a cidade de Viena estabeleceu sua própria companhia de seguros, que ainda hoje é um grande e bem-dirigido instituto de seguros, embora parcialmente privatizado na década de 1990. Para limitar ainda mais o poder da economia de mercado, a cidade de Viena estabeleceu um instituto bancário municipal para emitir obrigações hipotecárias mais baratas e seguras do que as oferecidas por instituições financeiras privadas" (MATTL, 2013, p. 203).

Revista de Direito da Cidade, vol. 08, no 3. ISSN 2317-7721 pp.859-885 
criação de meios que estimulem a produção habitacional e a compra (via financiamento) de imóveis urbanos ou rurais. ${ }^{12}$

Conforme o artigo 1ํㅡ, da referida Lei, a compreensão desta forma de se produzirem novas unidades residenciais e requalificação de imóveis (este último é aplicado aos imóveis urbanos) se dá pelo Programa Nacional de Habitação Urbana - PNHU (cf. inciso I do artigo 1ํ) e pelo Programa Nacional de Habitação Rural (cf. inciso II do artigo 1ํ). Além disso, o texto legal de que trata tal programa, ao abordar sobre a estrutura e finalidade do PMCMV, traz a configuração de medidas que visam a estimular a produção e aquisição de novas unidades habitacionais, para famílias com renda mensal de até $\mathrm{R} \$ 4.650,00$ (quatro mil, seiscentos e cinquenta reais), conforme preleciona o seu art.1ㅇ.

É preciso salientar que o PMCMV, por ser uma política voltada à aquisição de novas propriedades, seus beneficiários se tornam mutuários de programa de financiamento habitacional e serão futuros proprietários, não serão moradores (no sentido daquele que apenas mora, sem detenção de um título de propriedade que the assegure tal condição). Parcela ou um grupo que, ao longo da história da promoção de habitação, esteve excluída ou tinha pouca (na verdade, quase nenhuma) chance de acesso ao mercado formal, viu-se amparada por este programa (CARDOSO e JAENISCH, 2014, p. 8-9). Ou seja, ao financiar a unidade habitacional, o PMCMV transforma pessoas em futuros proprietários/mutuários de um financiamento habitacional e não apenas em moradores. Não há, portanto, promoção do direito autônomo à moradia. A promoção do direito à moradia vem a reboque de uma política habitacional que, embora se volte ao ideário de promover moradias, na verdade, acaba promovendo e reproduzindo a lógica da produção de novas propriedades.

O programa atual de financiamento habitacional se mostra satisfatório muito mais a quem o produz, ou seja, aos detentores dos meios de produção determinantes do mercado, os construtores, assim como às incorporadoras e aos bancos financiadores, ou seja, aos responsáveis por preparar os projetos, escolher os locais de onde será sua implementação e os que subsidiarão os gastos.

A forma estrutural do PMCMV foi idealizada de modo que a iniciativa privada comandasse toda pauta desta política habitacional. Segundo CARDOSO e JAENISCH (2014), ao atuarem como

\footnotetext{
12 Embora a Lei 11.977/2009 aborde a questão dos imóveis situados em zonas rurais, o objeto desta pesquisa está restrito apenas aos imóveis urbanos.
} 
promotores do programa, os agentes de mercado são capazes de orientar o sentido e direcionar os interesses envolvidos no tocante à produção das habitações.

Segundo tais autores, o direcionamento é dado de modo que todas as questões ligadas à dimensão social da moradia ficam "subordinadas a questões econômicas, seja no sentido do impacto quantitativo do programa, seja através das estratégias empresariais que buscam ampliar ao máximo a taxa de lucro e a produtividade" (CARDOSO e JAENISCH, 2014, p. 7). Conforme bem pontuaram, desde a idealização do programa até que ele seja colocado em prática, tudo é feito de modo a produzir um "pacote habitacional" para consumo: é o mercado, e não o Estado, quem tem o poder de decidir onde será realizada a construção do empreendimento, a quem será destinado (isto é, a faixa de renda para a qual o projeto residencial estará voltado), quais serão as características que o empreendimento terá, quem são as pessoas jurídicas responsáveis pela incorporação e pela construção etc. O Poder Público, na figura das entidades municipais, tem papel secundário ou de coadjuvante.

O Estado, na figura da União, despendeu recursos à habitação de interesse social de forma incomum e, nos dizeres de Cardoso e Jaenisch, num "volume inédito". O PMCMV tem, sem dúvida, a característica marcante de incluir, na política habitacional, recursos destinados à produção de moradias para população com renda familiar entre 0 e três salários mínimos. Esses recursos têm assegurado aos agentes privados de habitação (bancos, incorporadoras e construtoras) parcelas constantes de financiamento para a formação de um ciclo de produção de moradias, como também têm garantido que, na dimensão política, as Administrações sejam vistas como se estivessem interessadas em resolver a questão habitacional (CARDOSO e JAENISCH, 2014, p.7). ${ }^{13}$

Este protagonismo do mercado privado de habitação proporcionou a criação de conjuntos habitacionais extensos e cuja localização diz respeito às áreas menos valorizadas, localizadas em regiões cujo preço da terra é barato, "uma condição fundamental para a rentabilidade das operações -, reiterando um padrão histórico de ocupação do território onde o assentamento da população pobre é feito prioritariamente em periferias precárias e mal equipadas" (Rolnik et al, 2015, p.212).

A estrutura pensada para o programa não expressa a busca pela inclusão e integração ao tecido urbano, mas ratifica e perpetua a segregação socioespacial. Isso ocorre pelo fato de, ao se

\footnotetext{
${ }^{13}$ Não obstante, saliente-se que o mercado não tem costume de produzir moradias voltadas à essa faixa de renda. Estudos apontam que as habitações do PMCMV destinadas a famílias com renda inferior a três salários mínimos são produzidas em número ínfimo. A este respeito, cf. item 3 desta pesquisa.
} 
construir, não haver nenhuma preocupação em situar as novas unidades habitacionais em espaços dentro da cidade, mas às margens, onde o mercado econômico não tem interesse, não vê possibilidade de crescimento de seu lucro, como vê, por exemplo, em áreas ocupadas que representam uma boa localização, um dos principais motivos pelos quais a população de baixa renda é relegada: (des) interesse de localização.

Dessa forma, ao pensar no PMCMV, as políticas públicas, da forma como foram e estão estruturadas, se apresentam como mais um modo de expressar a segregação, pautado sob o alicerce de uma lógica discriminatória. Parece que o Poder Público, em suas ações, permite a promoção de políticas habitacionais em que a população de baixa renda é exilada, isto é, é posta em locais distantes das cidades, o que representa um profundo componente de ratificação e perpetuação da segregação socioespacial. Por conseguinte, aponta Maricato (2003, p. 163), a ascensão à qualidade de morador (isto é, colocar ao alcance moradias minimamente dignas, favorecidas pelo acesso aos serviços públicos de infraestrutura básicos) exige dois fatores condicionantes a serem vencidos, quais sejam "terra urbanizada e financiamento".

Tanto um como o outro fator foram, durante boa parte do desenvolvimento urbano do Brasil, componentes inalcançáveis pela população menos favorecida, que constituiu a esmagadora maioria da população brasileira. Assim, como afirma a autora, para democratizar a produção de moradias e garantir o acesso aos espaços urbanos servidos por infraestrutura, é preciso ultrapassar esses dois grandes obstáculos -terra urbanizada e financiamento- elementos que representaram, durante o processo de urbanização brasileira, categorias de bens proibidas a maior parte da população. Há a referência com relação ao contexto da relação a terra vestida por equipamentos públicos e não a nua (terra urbanizada), linhas de crédito de financiamento, bem como o Estado e o mercado: "O mercado privado não tem atingido nem mesmo a classe média (cinco a dez saláriosmínimos) quando a maior parte da população situada abaixo dos cinco salários mínimos necessita de subsídios" (MARICATO, 2003, p. 163).

O PMCMV, no tocante à presença desses protagonistas privados, se assemelhou bastante ao modelo do Banco Nacional de Habitação (BNH), fortalecido pela presença do empresariado da construção civil em parceria com os financiadores. Outra observação importante é que, seguindo a sistemática empresarial e econômica pensada em resultados rápidos, não foi capaz de estabelecer uma nova estrutura efetiva de planejamento urbano. Parece-nos que o PMCMV não se distanciou daquilo que já era empreendido pelo BNH, em 1964, apesar de difundir a propriedade privada da moradia em cerca de $80 \%$ dos empréstimos realizados em seus financiamentos, os mutuários 
pertenciam à faixa salarial de pelo menos 5 (cinco) salários mínimos, como afirma Abreu (2014, p. 233). Naquela época, as famílias mais necessitadas também não contavam com qualquer política habitacional que lhes fosse favorável.

O BNH, juntamente com o Sistema Financeiro de Habitação (SFH), cuja edição se deu pela Lei no 4.380/1964, ${ }^{14}$ objetivavam (à semelhança do que acontece no PMCMV) à promoção de construção e aquisição de "casa própria". Entre outros objetivos claramente pontuados em um relatório no ano de 1969, de acordo como o pontuado por Bollafi (1976), além da coordenação da Política Habitacional para o saneamento; melhoria no modelo habitacional e do ambiente, como a busca pela eliminação de favelas e demais assentamentos humanos no espaço urbano; o programa também visava à redução dos preços das novas residências a partir do aumento da oferta (frise-se: para reduzir o preço das moradias e garantir rentabilidade aos negócios, a indústria da construção civil precisava escolher locais estratégicos para a incorporação dos empreendimentos) e da economia de escala na produção. Outros fatores apontam a uma pseudopreocupação desta forma de financiamento bancário de habitação social, como é o caso, por exemplo, da redistribuição regional dos investimentos; progressivo aumento na aplicação de recursos às demais entidades administrativas, estados e municípios (BOLAFFI, 1976, p. 72-74).

Aliás, o modelo atual de provisão habitacional não se distanciou das ações voltadas à produção de moradia para atender o interesse social pensada a partir de 1930, segundo Botas e Koury (2014, p. 145-146), no Brasil, o direito à moradia aparece em marcos normativos a partir de 1930, com a inauguração do Ministério do Trabalho, Indústria e Comércio, nesse ano, pôde-se notar uma alteração na forma de controlar os recursos da Previdência Social, é possível perceber que diferente do que acontecia com os caixas sob o mando das empresas, a intervenção do Estado, com a criação de Institutos de Aposentadoria e Pensões, fez com que a fiscalização destes fundos pudessem, mais tarde, serem utilizados não apenas voltado à previdência dos trabalhadores, como foi o caso do financiamento de projetos de infraestrutura para o desenvolvimento industrial do país.

Afirmam as autoras que nem os Institutos nem as Caixas tinham como objetivo principal a promover a construção de moradias, tratava-se, portanto, de algo para além da função para que

14 Necessário observar que no que se refere à questão habitacional no brasil e a própria configuração de políticas públicas voltadas à habitação têm raízes no regime militar; nesse aspecto os urbanistas tratam do insucesso havido com a realização da produção habitacional aos moldes do previsto pelo BNH e SFH, pela relação extraída entre o preço do imóvel e poder aquisitivo das famílias de baixa renda ligados ao custo dos imóveis construídos que, diretamente refletiam na qualidade (distância da cidade, materiais utilizados etc.), sobre este aspecto concordamos com Maricato, 1987. 
foram instituídos, no caso, a de assegurar aposentadoria e pensões, a promoção dessas unidades residências e o financiamento era algo subsidiário. Essa função atípica destes fundos foi regulamentada posteriormente, em 1937, dentro das chamadas Carteiras Cambiais, pelas quais se regulavam os quesitos e condições a serem adquiridas as unidades habitacionais (BOTAS e KOURY, 2014, p.147-148).

Conforme aponta Bonduki (1994, p.724), a origem da produção da habitação nacional teve como marco o ano de 1937, momento em que foram regulamentadas as carteiras prediais dos Institutos de Aposentadorias e Pensões (IAPs) e quase uma década depois foi instituída a Fundação Casa Popular. A partir da década de 1930, passou a interessar aos grandes investidores do setor privado concentrarem seus investimentos na construção civil (construtores e incorporadores) e em formas de financiamento habitacional (bancos) para a produção de novas unidades residenciais a serem entregues para a camada de baixa renda, em detrimento à situação anterior, em que a produção destas casas objetivava a um futuro rendimento, o aluguel.

Como a Lei do Inquilinato no 4.598, editada em 1942, comprometeu essa prática ao estabelecer o congelamento dos aluguéis, o Poder Público passou a interferir no mercado de promoção de moradias, induzindo a produção de novas propriedades residenciais, desta vez voltadas à venda e não à locação. Por outro lado, houve a saída de alguns investimentos privados na produção habitacional, fazendo com que a indústria da construção civil, já interessada no recebimento de recursos públicos, passassem a integrar de modo protagonista e como forma de perpetuar essa atividade (angariando recursos e determinando a produção da habitação social), (BONDUKI, 1994, p.724-725).

Em 1946, ocorreu a criação da Fundação da Casa Popular, pelo Decreto-Lei no 9.777, que tinha por uma de suas finalidades a aquisição, construção e financiamento da casa própria (cf. art. $1{ }^{\circ}$, incisos ( e III), mediante atuação de empresas comerciais ou industriais, bem como outras instituições, ou sob responsabilidade de Prefeituras Municipais. Foi então configurada a primeira agência voltada à promoção de moradias para as camadas populares da sociedade brasileira.

O que se mostra relevante é que esses instrumentos de política habitacional foram responsáveis por fazer com que o Estado se mantivesse na condição de ator coadjuvante (frente ao protagonismo assumido pelos atores principais do mercado privado de habitação que, ao fabricar as novas moradias, definem desde a escolha da localização dos terrenos à entrega das chaves do imóvel) no cenário da produção de moradias subsidiadas, além de terem dado a possibilidade de financiamento habitacional a pessoas que antes não estavam incluídas em programas de aquisição 
de propriedade. Nesse sentido, não há muita diferença prática entre todos esses instrumentos e o PMCMV. Ainda que este preveja produção de moradias para população com renda inferior a três salários mínimos, esta produção não é efetivamente realizada, mantendo-se o déficit habitacional justamente na faixa de renda que mais depende de políticas habitacionais para promoção de seu direito fundamental à moradia.

\section{ANÁLISE DE DADOS SOBRE O DÉFICIT HABITACIONAL}

Os números colhidos por estudo realizado pela Fundação João Pinheiro (FJP. 2015, p. 3132), como estimativa para 2012, expressaram que o déficit habitacional brasileiro correspondia a 5,430 milhões de moradias, dentre eles cerca de 4,664 milhões, o equivalente a $85 \%$, estariam localizados em áreas urbanas.

Em termos regionais, o estudo ainda constatou que, em 2012, a questão do déficit habitacional em percentuais próximos a: 38,8\%, ou seja, 2,108 milhões de unidades encontravamse no Sudeste (deste número, 2,054 milhões de unidades habitacionais necessárias se localizam em áreas urbanas e apenas 54 mil em área rural); seguidos por 32,7\%, o tocante a 1,777 milhão de unidades (dentre as quais 1,238 milhão de moradias necessárias estariam em áreas urbanas, enquanto 538 mil moradias necessárias em áreas rurais), no Nordeste. Das cinco regiões do Brasil, o Sudeste e o Nordeste, juntos, lideram e representam 71,5\% de todo déficit habitacional do país.

No tocante a unidades da Federação, o que foi visto a respeito dos valores absolutos sobre o déficit habitacional foi uma maior expressividade em São Paulo. Nesse estado, a carência de novas unidades superava, em 2012, um milhão de moradias, precisamente 1,151 milhão ou 8,0\% dos "seus domicílios particulares permanentes e improvisados"; deste número, 582 mil unidades estariam destinados à região metropolitana de São Paulo. Em Minas Gerais, existiam 482 mil unidades em déficit habitacional, isto é, 7,3\%, dos quais, 136 mil localizadas na região metropolitana de Belo Horizonte. Seguido por: Maranhão, com cerca de 407 mil, 22,0\%; e Rio de Janeiro, na base de 397 mil, 7,1\%, em sua região metropolitana, o Rio de Janeiro apresentava o montante de 291 mil, o correspondente a 73\% do total do déficit do Estado. Em quarto lugar estaria a Bahia como estado da Federação com maior déficit absoluto, 379 mil moradias, 8,0\%, dentre elas 107 mil se concentravam na região metropolitana de Salvador. Com relação apenas às áreas urbanas, o estado do Amazonas em 2012 apresentava, expressivamente, o aproximado a $17,9 \%$ do estoque de domicílios urbanos. O estado do Acre compreendia 14,9\%; no Distrito Federal, a 14,5\%; no Maranhão, 13,7\%; em Roraima e Sergipe, a 13,0\%. 
Dentre as unidades da Federação com localização nas regiões Sul, Sudeste e Centro-Oeste, excluído o Distrito Federal, o déficit relativo é inferior a 10\%. Já na região Nordeste, apenas Ceará, Paraíba, Pernambuco e Bahia tiveram déficit relativo inferior a $10 \%$. Quanto às regiões metropolitanas, na de Belém, localizada na região Norte, o déficit correspondia a 10\% dos domicílios; na região metropolitana de Fortaleza, a 10,9\%. Nas demais regiões metropolitanas das regiões Nordeste, Sudeste e Sul, o déficit relativo era inferior a 10\%. O menor, 5,3\%, localizava-se na região metropolitana de Porto Alegre.

O outro alvo do estudo da FJP foi analisar o déficit habitacional urbano de acordo com a faixa de renda mensal referentes ao número de salários mínimos (FJP, 2015, p. 38), em termos metodológicos a divisão da análise tem como base a seguinte classificação: até três salários mínimos", "mais de três a cinco", "mais de cinco a dez", e "mais de dez". Dentre as famílias urbanas que mais carecem de moradias, as que se encaixam no grupo de "até três salários mínimos" concentravam 82,5\% do déficit habitacional; seguidas da classe dos que possuíam como renda "mais de três a cinco", contabilizando 10,1\% do déficit, as categorias com "mais de cinco a dez", correspondiam 5,6\% e a "mais de dez", compreendiam 1,8\%.

Nota-se, portanto, que as famílias possuidoras de renda de zero a três e as possuidoras de renda de três a cinco salários mínimos perfaziam juntas, em 2012, o total de 92,6\% do déficit habitacional urbano. Em outras palavras: pouco menos da totalidade do déficit habitacional nacional. Na região Nordeste, apesar de acompanhar as demais neste quesito, é peculiar, no sentido de que, possuía 88,4\% do déficit na classe de "até três salários mínimos" e 6,9\%, entre três e cinco salários mínimos. O que acontece, neste aspecto, nas regiões Sul e Sudeste, enquanto no grupo cuja renda é mais baixa (até três salários mínimos), a porcentagem é relativamente menor, 76,9\% e 80,6\% respectivamente, na categoria consecutiva os índices são mais elevados: $11,9 \%$ e $11,4 \%$ respectivamente. Os resultados referentes às camadas de renda superior a dez salários mínimos indicam que o déficit habitacional é pouco relevante, 1,8\% do déficit total, em 2012.

No último Censo Demográfico (IBGE, 2010b), realizado em 2010, do total de domicílios particulares recenseados havia o montante de 67.447.199 (em números absolutos), dos quais 57.541 .472 (83\%) se encontravam ocupados, 901.169 (1,34\%) em condição de "fechados", 2.932.990 $(5,83)$ destinados ao uso ocasional e 6.071 .568 (9\%) vagos. Conforme dados analisados pela FJP, a Pesquisa Nacional por Amostra de Domicílios - PNAD cujo escopo é produzir dados referentes ao desenvolvimento socioeconômico do País, em 2012, obteve-se o resultado de que o Brasil detém de 7,551 milhões de domicílios vagos. Segundo o estudo, "são considerados os 6,189 
milhões em condições de serem ocupados, os em construção ou reforma, que totalizam 1,008 milhão de unidades, e os 353 mil em ruínas" (FJP, 2015, p. 41).

O déficit habitacional dentre os números colhidos pela FJP é 5,430 milhões de domicílios, segundo estimativa do PNAD, no que tange aos domicílios brasileiros, representando cerca de $85,9 \%$ de unidades situadas em área urbana, é inferior ao número de domicílios vagos. A partir deste breve levantamento de números, podemos concluir que o déficit habitacional poderia ser suprimido, haja vista a quantidade imóveis não utilizados ser superior ao número de moradias necessárias para eliminar o déficit (e isto sem que fosse preciso contabilizar os domicílios de uso ocasional e em ruínas) (FJP, 2015, p. 97).

De fato, o programa de habitação Minha Casa Minha Vida se mostrou como proposta responsável por trazer a questão da moradia ao centro das agendas governamentais, possibilitouse o ingresso à moradia para a parcela da sociedade cuja renda era mínima, parcela esta representativa ao longo da história da camada excluída dos financiamentos para aquisição da casa própria. Contudo, não se pode afirmar que o PMCMV, da forma como vem sendo implantado (um teto e quatro paredes, de maneira pouco ou nada integrada ao tecido social), satisfaça à concretização da moradia adequada.

A Organização das Nações Unidas, por meio de seu Comitê de Direitos Econômicos, Sociais e Culturais, estabeleceu algumas Recomendações Gerais a respeito do Pacto Internacional dos Direitos Econômicos Sociais e Culturais, destacamos, em especial, a Recomendação de no 4 (do ano de1991), cuja redação cuidou da interpretação do art. 11.1 deste Pacto, ao definir e identificar os elementos acerca do que seria moradia adequada. Para o Comitê, o sentido a ser dado à moradia adequada é o de abranger outras postulações fundamentais, inerentes à condição humana (como o acesso a serviços públicos básicos, à saúde, à mobilidade, à educação bem como cultura, arte e lazer de modo a contribuir para uma maior integração ao meio social), no parágrafo 70 do mencionado comentário, afastou-se qualquer entendimento em sentido estrito ao salientar a impossibilidade de assimilar o direito à moradia ao abrigo constituído por um telhado e quatro paredes ou que o considere exclusivamente como uma mercadoria.

Por um lado, a inovação trazida pelo atual programa de financiamento habitacional, ao subsidiar créditos para a população de baixa renda, com o intuito de que as necessidades habitacionais de aquisição de unidades residenciais fossem supridas, conseguiu alcançar a parcela demandante de maiores condições de financiamento e barateamento para a compra de imóveis; por outro lado, não considerou questões voltadas à integração socioespacial destas novas unidades 
residenciais, no sentido de estarem pensadas dentro de uma política urbana e habitacional capaz de tornar universal o alcance à moradia como um direito fundamental, dentro de condições adequadas, "tendo negligenciado o enfrentamento do problema da segregação socioespacial em função da renda nas cidades brasileiras" (Rolnik, 2015, p. 128). Neste sentido, é possível afirmar que o PMCMV não resolve o déficit habitacional da população mais necessitada, haja vista que não existem políticas públicas de promoção de moradia pela moradia, ou mesmo financiamentos imobiliários feitos a um público sem renda.

As moradias que têm sido implementadas pelo PMCMV não resolvem o problema do déficit habitacional e não resolvem o problema da população mais necessitada. Quanto à parcela da população que tem condições de financiar propriedades imobiliárias (serviço pelo qual a moradia é transferida a reboque, em conjunto com a propriedade do imóvel financiado), a quantidade maximizada de habitações às margens da cidade, sem preocupação nenhuma em se estabelecer a materialização do direito à moradia de forma autônoma, de maneira minimamente integrada ao tecido social (tecido urbano). As pessoas beneficiárias do PMCMV são postas na periferia, longe da presença de quaisquer elementos de integração social ou cultural, relegadas ao entorno excluído da cidade. Portanto, o Poder Público o maior responsável por promover políticas de inclusão, seguindo perspectivas diversas e distantes do interesse público, acaba por excluir.

Em que pese o Estado prever a inclusão de certas pessoas no PMCMV, a lógica desse programa habitacional exclui essas pessoas duas vezes. A primeira exclusão está na forma de acesso à terra. Os conjuntos residenciais são construídos em terras distantes e pouco urbanizadas, justamente para permitir que a construção seja rentável. Com terra barata, o custo de produção é menor e a chance de vender as unidades habitacionais é maior. Terra distante, porém, é sinônimo de exclusão do morador à estrutura da cidade. A falta de equipamentos e serviços públicos impede que os moradores dos PMCMV tenham um mínimo de contato com a cidade e um mínimo de exercício de direitos básicos de sua cidadania.

A segunda exclusão se dá na hora do financiamento. As pessoas que mais precisam morar são as últimas que terão seu cadastro aceito pelas instituições bancárias responsáveis pelo financiamento das unidades residenciais. Ainda que as residências não possam ser consideradas como moradias adequadas (na forma da Resolução 4 do Comitê das Nações Unidas), trata-se de moradias que somente serão concedidas a pessoas que puderem demonstrar alguma capacidade econômico-financeira para quitação de financiamento bancário. A população mais carente, e que vive em situação de maior vulnerabilidade, não será elegível para se mudar para as novas unidades 
residenciais, simplesmente porque não têm como provar condições econômicas para quitar obrigações bancárias.

Um grande obstáculo à concretização do Direito à cidade é a questão da moradia deficitária. Se, do contrário, fosse dito "questão do déficit de moradia", a discussão poderia ter um rumo pouco diverso, como por exemplo, poderia levar à discussão a respeito do número insuficiente de unidades residenciais, isto é, estar-se-ia abordando a falta em razão de sua exiguidade e não de sua satisfatoriedade.

Não obstante, a pretensão em falar "moradia deficitária" em vez de "déficit de moradias" serve para pôr foco sobre a qualidade e não a quantidade de unidades habitacionais. O direito à moradia adequada é um problema muito mais relacionado à qualidade (ou à falta dela) que à quantidade, e se refere à necessidade de as unidades habitacionais serem planejadas e construídas de forma integrada aos demais fatores expressivos da cidade. Algo que não acontece, por exemplo, no âmbito do Programa Minha Casa Minha Vida.

São diversos os fatos que impedem e inviabilizam a identificação da cidade como um direito, desde o acesso à moradia adequada, a fatores que também se relacionam com a questão da segregação social e espacial (revela-se então a questão da localização como condicionante à promoção do direito à cidade), assim como a organização e reestruturação do espaço urbano público no tocante à necessidade de se pensar numa política de regularização fundiária mais incisiva.

O papel do administrador tem destaque nessa conjuntura, ao passo que é a ele reservada a prerrogativa de discricionariedade para determinar a destinação dos gastos e definição de políticas públicas para a construção e o uso do espaço urbano. No entanto, por razão deste estudo e por força da teoria dos direitos fundamentais, indaga-se a respeito de não haver nenhuma mitigação a este juízo de conveniência e oportunidade, de modo a impor ao gestor da coisa pública o dever de realizar políticas públicas essenciais à concretização de direitos sociais. Indaga-se o dever do Administrador de realizar o planejamento urbano (Estatuto da Cidade, artigos. 2으, IV, 4으, II e III, e 40 , I) não seja minimamente vinculado ao dever de produzir a cidade para as pessoas, visando à inclusão destas de modo adequado no espaço urbano e promovendo sua permanência.

Com relação ao PMCMV, principal programa federal de habitação vigente. No Brasil, é realizada por meio de financiamento, via PMCMV, em que a propriedade é transferida e o indivíduo não se torna simplesmente um morador (ainda que vá residir naquele lugar), mas um proprietário/mutuário. Ou seja, o principal programa de oferta de moradias do Brasil, a exemplo de 
outros estudados cuja base está no uso, como a concessão de uso especial para fins de moradia (artigos 15 ao 20 do Estatuto da Cidade) e a concessão de direito real de uso (artigo 4ㅇ, V, $g$ desse mesmo Estatuto) bem como a instituição de Zonas Especiais Interesse Social (artigo 4ํ, V, f, do Estatuto da Cidade), nota-se que se trata de entrega de propriedades imobiliárias e não de residências, ou seja, revela-se um interesse privado de produção de propriedades, ainda que haja menção na instituição do Programa em se alcançar o déficit de moradias, "em atenção" ao direito à moradia.

Sobre a questão da moradia, permanecem atuais as considerações de Engels (2015), resultado de publicações no Jornal do Partido Operário Social-Democrata, entre os anos de 1872 e 1873. Entre outras coisas, Engels condensa o problema da posse (e sua desvalorização) e a solução dada, tanto pela pequena como pela grande burguesia, com relação à moradia, pela entrega do título de propriedade (2015, p. 29-36); também aborda a questão da escassez da moradia e o fato de que existe espaço físico suficiente para remediar o problema, como a utilização mais racional destes espaços (em outras palavras, a destinação dos espaços urbanos privados -muitos vezes ociosos- ao uso, à utilização minimamente voltada ao interesse social/público/coletivo, ainda que saibamos que não existe racionalidade em decisões políticas, submetidas ao crivo de prerrogativas do Administrador, como a discricionariedade); e aponta que esta escassez é essencial para a manutenção da forma burguesa em estruturar a sociedade, lógica voltada à preservação de uns interesses em detrimento de outros, logo, não sendo obra do acaso, mas algo imprescindível (2015, p. 71).

Segundo entendimento desse autor, o problema não é sequer de déficit de moradias, mas sim de uma estrutura fundiária que impede a fixação do pobre na terra urbanizada. Desde 1873 até hoje, parcela da doutrina -Engels (2015); Harvey (2005, 2013); Lefebvre (2001); Maricato (1987; 2013); Santos (1998) - vêm encarando a forma da manutenção de interesses como algo crucial à definição da organização do espaço urbano. Tem sido constatado que o espaço urbano é um espaço de apropriação que impede a geração de áreas de convivência. A cidade apropriada acaba sendo entendida, organizada e vivida não como espaço social, mas como um centro potencialmente (e efetivamente) capaz de reproduzir as relações de dominação estabelecidas pelos protagonistas do mercado.

Isso fica muito claro na realidade da política habitacional de financiamento de propriedades, incluindo-se aqui o PMCMV, em que não se pensa na localização das futuras moradias, nem se a terra é servida por urbanização, mas, tão somente na lucratividade que o 
acesso a conta-gotas à urbanização poderá gerar. É isso o que acontece com a entrega do título de propriedade em vazios periféricos, verdadeiras margens da centralidade urbana e das possibilidades de um espaço social como forma de centro de convívio social. A população de baixa renda não só fica exilada em conjuntos habitacionais promovidos pela atuação em conjunto (Poder Público + agentes de mercado), como amarrada a um modelo estruturado sob a escassez de recursos públicos como forma de justificação de manutenção do estado de coisas.

\section{CONSIDERAÇÕES FINAIS}

O déficit habitacional envolve questões ligadas tanto à qualidade quanto à quantidade, mas não é a produção maximizada de unidades habitacionais que resolverá toda esta problemática. Não dá para afirmar que a política de financiamento é eficaz pelo fato de estar produzindo moradias em todos os vazios que ainda não foram escolhidos pelo mercado para valorização. Em outras palavras, não se resolve o déficit habitacional apenas com a produção de novas unidades em locais de (des) interesse por aqueles que as produzem. Atingir certo número de unidades residenciais é eficaz apenas para encarar a moradia como mercadoria, o que traduz a razão de ser na construção de conjuntos habitacionais longe dos espaços urbanos - ainda que existam os chamados espaços vazios urbanos.

A produção quantificada é satisfatória (e, aí, eficaz) muito mais em relação aos agentes de mercado, algo que a distância sobremaneira daquilo que lhe dá legitimidade, qual seja, a promoção do direito à moradia. Porém, ao contrário do que legitima os programas habitacionais, e no sentido pontuado por Lefebvre (2008, p. 26-27), reduz-se a moradia à condição de produto, assim como a parte da cidade destinada aos programas habitacionais também é encarada como mercadoria, comprometendo, se não impedindo, que a cidade se torne a possibilidade de convívio e de experimentação da urbanidade.

Na busca para suprir o déficit de moradia, talvez a entrega de um título de moradia (de posse) e não de propriedade já fosse suficiente. O imóvel entregue ao morador cumpriria a função social de the abrigar sem necessidade de se transferir propriedade. O imóvel seria compreendido dentro de uma lógica em que ele seria aproveitado segundo a finalidade da moradia, sem se submeter à lógica de mercado. Mas encarar as políticas habitacionais pela moradia não interessa aos agentes do mercado imobiliário.

Sempre haverá aquelas pessoas que não poderão pagar pela propriedade imobiliária, e isso retira dessas pessoas o efetivo acesso ao direito fundamental à moradia', que não deveria, 
portanto, estar submetido à pecúnia. No entanto, mesmo com o advento do PMCMV, não há nenhuma política de criação de espaço de moradias, não há efetivamente um direito à moradia sendo promovido, já que o que se concede pelo PMCMV é um direito de propriedade, e não de posse.

Dentro da lógica do capitalismo, não se entende, não se compreende o simples morar sem o título de propriedade. Não existe título de morador. Não faz sentido entregar a posse concreta (ou a moradia) sem entregar a propriedade privada (do imóvel em que se pode residir). Segurança da posse, ao fim e ao cabo, é o título jurídico de proprietário.

É possível afirmar, portanto, ao menos em relação a promover efetivamente o direito à moradia, já que o PMCMV serve primeiramente à produção de propriedades e à sua financeirização, que o Programa federal não é nem minha casa, muito menos minha vida. A moradia se apresenta muito mais como um pretexto para o mercado funcionar e gerar lucro para seus agentes, em especial as incorporadoras, as construtoras e os bancos.

\section{BIBLIOGRAFIA}

\section{Normas e documentos públicos oficiais}

BRASIL. ASSEMBLEIA NACIONAL CONSTITUINTE, Constituição da República Federativa do Brasil, 1988. Disponível em: http://www.planalto.gov.br/ccivil_03/Constituicao/Constituicao.htm Acesso em 04 de março de 2016.

CONGRESSO NACIONAL. Lei no 10.406/2002, Código Civil. Disponível em: http://www.planalto.gov.br/ccivil_03/leis/2002//10406.htm Acesso em 28 de maio de 2016. CONGRESSO NACIONAL. Lei no 10.257/2001, Estatuto da Cidade. Disponível em http://www.planalto.gov.br/ccivil_03/leis/LEIS_2001/L10257.htm Acesso em 04 de março de 2016. CONGRESSO NACIONAL. Lei no 6.766 de 1979, Parcelamento do Solo Urbano. Disponível em: http://www.planalto.gov.br/ccivil_03/leis/L6766.htm Acesso em 28 de maio de 2016.

CONGRESSO NACIONAL. Lei no 11.977/2009, Programa Minha Casa Minha Vida. Disponível em: http://www.planalto.gov.br/ccivil_03/_ato2007-2010/2009/lei/l11977.htm Acesso em 25 de fevereiro de 2016.

CONGRESSO NACIONAL. Lei № 11.124/2005, Sistema Nacional de Habitação de Interesse Social. Disponível em: http://www.planalto.gov.br/ccivil_03/_ato2004-2006/2005/lei/l11124.htm. Acesso em 26 de março de 2016

INSTITUTO BRASILEIRO DE GEOgRAFIA E ESTATÍSTICA. Censo Demográfico 2010. Características Urbanísticas do entorno dos domicílios. 2010, p. 1-175. Disponível em: ftp://ftp.ibge.gov.br/Censos/Censo_Demografico_2010/Entorno_dos_Domicilios/entorno.pdf. Acesso em 02 de julho de 2015.

INSTITUTO BRASILEIRO DE GEOGRAFIA E ESTATÍ́STICA (IBGE). Censo Demográfico de 2010. Primeiros resultados. População e Domicílios recenseados. 2010b. Disponível em: 
http://www.ibge.gov.br/home/presidencia/noticias/imprensa/ppts/0000000237.pdf. Acesso em 02 de julho de 2015.

FUNDAÇÃO JOÃO PINHEIRO. Centro de Estatística e Informações. Déficit habitacional no Brasil 2011-2012. Belo Horizonte, 2015. Disponível em: http://www.fjp.mg.gov.br/index.php/produtos-eservicos1/2742-deficit-habitacional-no-brasil-3. Acesso em 02 de abril de 2016.

ORGANIZAÇÃO DAS NAÇÕES UNIDAS. COMITÊ para os Direitos Econômicos, Sociais e Culturais.

Recomendação Geral $\quad$ n. 4.41991 .4 Disponível em: http://tbinternet.ohchr.org/_layouts/treatybodyexternal/Download.aspx?symbolno=INT\%2FCESCR \%2FGEC\%2F4759\&Lang=en (em inglês). Acesso em 10 de março de 2016.

Recomendação Geral n. 7. 1997. Disponível em: http://naroman.tl/pdhj/unhrt/UNHRT/pdhj.org/unt/documents/PIDESC\%20CG\%207_p.pdf. Acesso em 10 de março de 2016.

\section{Referências Bibliográficas}

ABREU, João Maurício Martins de. A construção histórica do modelo proprietário no Brasil: Uma hipótese sobre o direito à moradia. Revista Direito e Práxis Vol. 5, n. 8, 2014, pp. 213-239. Disponível em: http://www.e-publicacoes.uerj.br/index.php/revistaceaju/article/view/7354/9252. Acesso em 10 de abril de 2016.

A moradia informal no banco dos réus: discurso normativo e prática judicial. Revista de Direito GV no14. São Paulo, 2011, p. 391-415. Disponível em: http://direitosp.fgv.br/sites/direitosp.fgv.br/files/03_rev14_391-416_-

joaao_mauriucio_martins_de_abreu___scielo.pdf. Acesso em 10 de abril de 2016.

AMORE, Caio Santo. SHIMBO, Lucia Zanin. RUFINO, Maria Beatriz Cruz (Org.). Minha Casa... E acidade? Avaliação do Programa Minha Casa Minha Vida em seis estados brasileiros. Rio de Janeiro: Letra Capital, 2015.

BOLAFFI, Gabriel. Habitação e urbanismo: o problema e o falso problema. Cadernos, Centro de Estudos Rurais e urbanos. v. 9, p. 65-85, 1976. Disponível em: http://www.revistas.usp.br/cerusp/article/view/83167/86202 Acesso em 01 de junho de 2016.

BONDUKI, Nabil Georges. As origens da habitação social no Brasil. Análise Social, vol. XXIX (127), $1994 \quad\left(3 .^{\circ}\right), \quad$ p. 711-732. Disponível em: http://analisesocial.ics.ul.pt/documentos/1223377539C9uKS3pp5Cc74XT8.pdf. Acesso em 14 de março de 2016.

BOTAS, Nilce Cristina Aravecchia. KOURY, Ana Paula. A cidade industrial brasileira e a política habitacional na Era Vargas (1930-1954). Urbana, v.6, no 8, jun.2014 - Dossiê: Cidade e Habitação na América Latina - CIEC/UNICAMP. Disponível em http://www.ifch.unicamp.br/ojs/index.php/urbana_old/article/viewFile/1721/pdf. Acesso em 10 de abril de 2016.

CARDOSO, Adauto Lúcio e JAENISCH, Samuel Thomas. Nova política, velhos desafios: problematizações sobre a implementação do programa Minha Casa Minha Vida na região 
metropolitana do Rio de Janeiro. e-metropolis: Revista eletrônica de Estudos Urbanos e Regionais, v. 5, p. 6-19, 2014.2 Disponível em: http://emetropolis.net/system/edicoes/arquivo_pdfs/000/000/018/original/emetropolis_n18.pdf? 1447896374. Acesso em 27 de maio de 2016.

ENGELS, Friedrich. Sobre a questão da moradia. Tradução de Nélio Schneider. São Paulo: Boitempo, 2015.

HARVEY, David. A produção capitalista do espaço. Tradução Carlos Szlak. São Paulo: Annablume, 2005.

Ciudades rebeldes: Del derecho de la ciudad a la revolución urbana. Tradução para o espanhol Juanmari Madariaga. Madrid: Akal, 2013.LEFEBVRE, Henri. Direito à Cidade. Tradução Rubens Eduardo Frias. 5ạ ed. São Paulo: Centauro, 2008.

MARICATO, Ermínia. Metrópole, Legislação e Desigualdade. Estudos Avançados, São Paulo, n. 17 (48), 2003, p. 151-167. Disponível em: http://www.scielo.br/pdf/ea/v17n48/v17n48a13.pdf. Acesso em 27 de março de 2016.

A ideias fora do lugar e o lugar fora das ideias. IN: ARANTES, Otília; VAINER, Carlos; MARICATO, Ermínia. A cidade do pensamento único: Desmanchando consensos. 8 ed. Petrópolis: Vozes, 2013.

Política habitacional no regime militar: do milagre brasileiro à crise econômica. Petrópolis: Vozes, 1987.

MARRA, Natalia Cardoso e GONÇALVES, Raquel Garcia. O desafio da efetivação do direito à cidade nas grandes metrópoles, Revista Tecer, Belo Horizonte, 2011, v.4, n.7, p. 58-70Disponível em: DOI: http://dx.doi.org/10.15601/1983-7631/rt.v4n7. Acesso em 1ํo de maio de 2016.

MASTRODI, Josué e BATISTA, Ana Carolina. Existe um direito fundamental à posse? Estudo sobre a relativização do conceito de propriedade imobiliária urbana em face do direito de moradia. Revista de Direito da Cidade, v.7, n. 4, 2015, p. 1527-1554. Disponível em: http://www.epublicacoes.uerj.br. Acesso em 14 de fevereiro de 2016.

MASTRODI, Josué e MARTINS, Gabriela Isaac. A construção do direito à cidade entre o interesse público e o interesse dos agentes do mercado imobiliário: um estudo de caso a partir do plano local de gestão de barão Geraldo, em Campinas. Revista de Direito da Cidade, v.8, n. 2, 2016, p. 728-748. Disponível em: http://www.e-publicacoes.uerj.br/index.php/rdc/article/view/21772. Acesso em 27 de maio de 2016.

MASTRODI, Josué e RODRIGUES, Mônica Nogueira. A vinculação do Administrador às leis orçamentárias como meio de concretizar o direito fundamental à moradia: Estudo sobre controle de políticas públicas de moradia no município de campinas. Revista Direitos Fundamentais \& Democracia, v. 19, n. 19, 2016, p. 3-21. Disponível em: http://revistaeletronicardfd.unibrasil.com.br. Acesso em 10 de abril de 2016.

MASTRODI, Josué e ROSMANINHO, Mariane Dantas. O direito fundamental à moradia e a existência da reserva do possível. Revista Direitos Fundamentais \& Democracia, v. 14, n. 14, 2013, p. 113-134. Disponível em: http://revistaeletronicardfd.unibrasil.com.br. Acesso em 10 de fevereiro de 2015. 
MASTRODI, Josué e ROSSI, Renan Alarcon. Direito Fundamental Social à Moradia: aspectos de efetivação e sua autonomia em relação ao direito de propriedade. Revista Direitos Fundamentais \& Democracia, v. 19, n. 19, 2015, p. 145-167. Disponível em: http://revistaeletronicardfd.unibrasil.com.br. Acesso em 10 de fevereiro de 2015.

MASTRODI, Josué e SILVEIRA ZACCARA, Suzana Maria Loureiro. Sobre a Promoção do Direito à Moradia: Um estudo à luz da Política Urbana do Município de Campinas. Revista Direito da Cidade, v. 8, n. 1, 2016, p. 1-28. Disponível em: http://www.e-publicacoes.uerj.br. Acesso em 14 de fevereiro de 2016.

Sobre a compreensão da cidade como um direito a partir do reconhecimento da cidade como fenômeno social, mimeo, 2015.

MATTL, Siegfried. O caso da Viena Vermelha. Lua Nova [online], n. 89, 2013, p.191- 213. Disponível em: http://dx.doi.org/10.1590/S0102-64452013000200008. Acesso em 10 de março de 2016.

MEIRELLES, Hely Lopes. Direito de Construir. Revisão atualizada por Eurico de Andrade Azevedo, 7ạ ed. São Paulo: Malheiros, 1996.

Direito municipal brasileiro. Revisão atualizada por Márcio Schneider Reis e Edgard Neves da Silva. 16ạ ed. São Paulo: Malheiros, 2008.

MOURA, Emerson Affonso da Costa e MOTA, Maurício Jorge Pereira da. O Direito à moradia digna na regularização fundiária da Lei Federal n. 11.955/2009: O caso do auto de demarcação da comunidade da Rocinha. Revista de Direito da Cidade, v.7, n. 4, 2015, p. 1292-1310. Disponível em: DOI: 10.12957/rdc.2015.18848 Acesso em 28 de maio de 2016.

ROLNIK, Raquel; PEREIRA, Alvaro Luis dos Santos; MOREIRA, Fernanda Accioly; ROYER, Luciana de Oliveira; IACOVINI, Rodrigo Faria Gonçalves; NISIDA, Vitor Coelho. O Programa Minha Casa Minha Vida nas regiões metropolitanas de São Paulo e Campinas: aspectos sócio-espaciais e segregação. Cad. Metrop., São Paulo, v. 17, n. 33, 2015, p. 127-154. Disponível em: http://dx.doi.org/10.1590/2236-9996.2015-3306. Acesso em 02 de abril de 2016.

SALDANHA, Nelson. A cidade e a praça: Ensaio sobre o lado privado e o lado público da vida social e histórica, Porto Alegre: Sergio Antonio Fabris Editor, 1986.

SANTOS, Milton. A urbanização brasileira. 4a ed. São Paulo: Hucitec, 1998;

SINGER, Paul. Economia Política da Urbanização. 10ạ ed. São Paulo: Brasiliense, 1985.

TRINDADE, Thiago Aparecido. Direitos e Cidadania: Reflexões sobre o direito à cidade. Lua Nova, $n$. 87, 2012, p. 139-165. Disponível em: http://www.scielo.br/pdf/ln/n87/07.pdf. Acesso em 10 de abril de 2016.

Trabalho enviado em 15 de abril de 2016.

Aceito em 09 de junho de 2016. 